\title{
Novas (re)configurações no Ministério da Educação: entre o fio de Ariadne e a mortalha de Penélope
}

\author{
GIOVANI FERREIRA BEZERRA \\ Universidade Federal de Mato Grosso \\ do Sul, Naviraí, MS, Brasil \\ DORACINA APARECIDA DE CASTRO ARAUJO \\ Universidade Estadual de Mato Grosso \\ do Sul, Paranaíba, MS, Brasil
}

\begin{abstract}
Encontramo-nos num momento de encruzilhada paradigmática na educação especial. [...]. Hoje, a educação especial, como área (ou subárea?) de conhecimento, teórica e aplicada, encontra-se num verdadeiro processo de crise de identidade (e de continuidade?)

Beyer, 2010, p. 5
\end{abstract}

\section{INTRODUÇÃO}

No Brasil, atualmente percebemos um aumento da tensão acerca das políticas educacionais inclusivas delimitadas pelo Ministério da Educação (MEC), alvo de críticas por uma parcela significativa de educadores e especialistas em inclusão escolar. Nesse cenário conturbado, em que se opõem defensores ultrarradicais de uma escola inclusiva e vozes mais prudentes, entendemos que seja imprescindível provocar uma reflexão acerca das últimas ações do MEC. 
Esse ministério promoveu a extinção da antiga Secretaria de Educação Especial (SEESP) para introduzir os assuntos de sua competência na estrutura da Secretaria de Educação Continuada, Alfabetização, Diversidade e Inclusão (SECADI), perante o decreto presidencial n. 7.480, de 16 de maio de 2011, que passou a vigorar a partir de 23 de maio de 2011. Posteriormente, esse diploma legal foi revogado pelo decreto n. 7.690, de 2 de março de 2012, que, entretanto, trouxe discretas alterações na composição da recém-criada SECADI, mantendo, em linhas gerais, as mesmas proposições do decreto n. 7.480 no que tange à estrutura e função de tal secretaria. Convém assinalar que esta surgiu, por sua vez, da reestruturação realizada na ex-Secretaria de Educação Continuada, Alfabetização e Diversidade (SECAD), à qual se "acrescenta" o eixo da inclusão (Brasil, 2011a, 2012).

Interessa-nos compreender, ao menos em parte, algumas nuances da mais nova reestruturação ministerial e as possíveis repercussões dessa medida no campo dos estudos em educação especial e inclusiva, tomando-se por base o agravamento das contradições no que tange às políticas públicas ultimamente delineadas no país. No decorrer da análise, assumimos uma postura crítico-dialética. Posicionamo-nos contra a disseminação de uma perspectiva idealista no cenário pedagógico brasileiro, a qual tem subordinado a inclusão escolar de pessoas com deficiência ao igualitarismo formal e peseudodemocrático. E, na direção de buscar significados e sentidos para um processo recente de mudança, recorremos, ao longo do texto, a analogias com as histórias de Ariadne e Penélope, exploradas metaforicamente.

Para situar o leitor, lembramos que, segundo a mitologia grega, havia na ilha de Creta uma criatura monstruosa, metade homem e metade touro, o Minotauro, fruto da relação entre Pasífae, mulher do rei Minos, e um touro, que seria destinado em sacrifício ao deus Possêidon. Envergonhado com essa situação, Minos, o soberano traído, ordena a seu arquiteto, Dédalo, a construção de um gigantesco labirinto, para lá encerrar o Minotauro. Após sua vitória sobre os atenienses em uma das tantas batalhas contra as cidades gregas, Minos impõe ao povo de Atenas que envie, a cada ano, sete rapazes e sete moças para alimentar o monstro. Depois de muitas mortes, $o$ ateniense Teseu decide finalmente enfrentar a criatura lendária, na tentativa de resgatar a tranquilidade de seu povo (Vasconcellos, [1998]).

Chegando a Creta, Teseu imediatamente desperta a paixão de Ariadne, a filha de Minos com Pasífae. A moça, temendo que o amado se perdesse no labirinto, entrega-lhe um novelo para ser desenrolado à medida que ele avançasse em sua caminhada por aquele lugar terrível. O plano funciona muito bem. Após enfrentar o Minotauro e matá-lo, Teseu consegue facilmente reencontrar o caminho de volta, recuperando o fio da meada, que, certamente, descrevera um enorme emaranhado (idem). Com base nessa narrativa, popularizou-se a expressão que, neste texto, usamos com forte apelo metafórico, isto é, a ideia de "recuperar o fio de Ariadne" em situações que lembram verdadeiros "labirintos", haja vista o aspecto intrincado dos fatos e fenômenos considerados.

Entendemos que a trajetória da educação especial e das políticas que a sustentaram - e ainda sustentam -, seguiram, em muitas ocasiões, esse caminho 
confuso e sinuoso, com idas e vindas, conforme sintetiza a imagem do labirinto: lugar que incomoda, assusta e, por vezes, parece não ter saída possível, confundindo-nos sempre, adiando a chegada. No interior desse "labirinto", seguindo o novelo emaranhado das políticas públicas, percebemos que "[...] as alterações de status dado ao órgão responsável pelo equacionamento da educação de crianças e jovens com necessidades educacionais especiais no país tem [sic] refletido o grau de prioridade dado a esta questão pelos diferentes governos" (Manifesto..., 2011). Isso ocorre também no governo atual, que no cenário educacional não deixa de efetivar uma política contraditória, notando-se significativa desvalorização da educação especial, combinada com certo autoritarismo, à medida que "[...] tem tentado consistentemente impingir aos sistemas uma diretriz política não consensual, fundamentada no princípio da inclusão total, o que tem prejudicado o processo de construção da inclusão escolar na realidade brasileira [...]” (idem).

Para avaliar o panorama hodierno, entretanto, sem o risco de julgamentos apressados, torna-se fundamental perceber como se foram produzindo as políticas brasileiras de educação especial e os órgãos administrativos encarregados de sua gestão. Dessa forma, podemos ter mais clareza para analisar suas implicações mais recentes para a escola inclusiva. No percurso traçado para objetivar tal análise, vamos enrolando mais um pouco o fio de Ariadne, que nos conduzirá por uma viagem mitológica, de caráter heurístico, no decorrer da qual refletiremos sobre rumos já tomados e outros que poderiam ser adotados, servindo-nos de breves apontamentos históricos como ponto de partida. Acreditamos que é fundamental o regresso ao princípio do labirinto, para, de lá, vislumbramos outras projeções.

\section{RETOMANDO O FIO DE ARIADNE: NOTAS HISTÓRICAS SOBRE A EDUCAÇÃO ESPECIAL NO BRASIL}

Não temos, porém, a intenção de realizar uma ampla retomada histórica acerca das políticas públicas em educação especial e inclusiva no Brasil. Parte considerável desse trabalho está disponível nos estudos já sistematizados por pesquisadores de grande envergadura científica (Bueno, 1993; Januzzi, 2006; Mazzota, 2005). Por isso, não nos parece necessário realizar novamente, in totum, essa tarefa, reservando-nos apenas o direito de contextualizar a problemática com breves notas históricas, que trarão alguma clareza para o entendimento da recente conjuntura política do MEC, tomada como objeto de investigação neste artigo, naquilo que concerne à extinção da SEESP.

Assim, gostaríamos de (re)lembrar que, no caso brasileiro, o delineamento de um órgão ministerial responsável pela educação especial aparece apenas a partir dos anos de 1970, com a criação, em 1973, do Centro Nacional de Educação Especial (CENESP), àquela época vinculado ao então Ministério da Educação e Cultura. O CENESP, instituído pelo decreto n. 72.425, de 3 de julho de 1973, em plena ditadura militar, durante o governo do presidente Emílio Garrastazu Médici, tinha uma orientação política fortemente marcada pela institucionalização dos serviços 
e espaços da educação especial, entendidos como preparatórios para a entrada dos alunos deficientes no ensino comum (Brasil, 1973).

Vivia-se, naquele momento, o auge do período integracionista. Alunos com deficiência deveriam primeiro passar pelo treinamento da educação especial. Apesar disso, o suposto período propedêutico prolongava-se, na maioria das vezes, por toda a vida escolar dos alunos com deficiência, reforçando uma dicotomia entre escola comum e escolas/classes especiais - além de servir como depósito legalizado de alunos considerados desviantes pelo sistema escolar.

Em 1986, pelo decreto n. 93.613, de 21 de novembro, o CENESP foi transformado, durante o mandato presidencial de José Sarney, na Secretaria de Educação Especial (SESPE), vinculada à diretoria superior do MEC (Brasil, 1986). Com essa reviravolta, a educação especial vai, aos poucos, assumindo certa importância e notoriedade na hierarquia do ministério.

Em 1990, no governo de Fernando Collor, a SESPE foi extinta. Com isso, o fio de Ariadne dá mais voltas; as funções da antiga secretaria de educação especial são remanejadas para a Secretaria Nacional de Educação Básica (SENEB), conforme o decreto n. 99.678, de 8 de novembro de 1990 (Brasil, 1990). Não obstante as críticas direcionadas a mais uma mudança, dando a impressão de não se saber aonde levar a educação especial ou, em sentido figurado, de não se saber como encontrar a saída do labirinto, essa aproximação da educação especial com a educação básica, na mesma pasta, revela, historicamente, uma tímida tentativa de se superar a velha dicotomia entre ensino regular e especializado na educação nacional. Já transparece aí, ao menos em termos administrativo-gerenciais, a ideia de se situar a educação especial como modalidade, transversal às etapas básicas da escolarização formal. Em outras palavras,

Esta alteração estrutural sugere a preocupação com a integração da Educação especial com os demais órgãos centrais da administração do ensino. Pelo menos por sua localização na estrutura do MEC, a Educação especial deixa de ser objeto de um órgão autônomo em relação aos níveis e demais modalidades de ensino. (Mazzotta, 2005, p. 81)

Retomando outros fios da meada, a fim de, assim como Teseu, buscarmos a saída do labirinto, vale dizer, para alcançarmos a realização do objetivo proposto para ser discutido neste texto, avançamos mais alguns passos na breve cronologia delineada. Outro fato importante (ou mais um fio do novelo) de destaque no cenário político-educacional brasileiro foram os episódios políticos do ano de 1992. Com a saída do presidente Collor, a educação especial, que desde o final de 1990 estivera a cargo da SENEB, volta a ser representada por uma secretaria específica. $\mathrm{Na}$ verdade, ressurge a secretaria de educação especial, mas agora rebatizada pela sigla SEESP (Brasil, 1992). E assim permaneceria até maio de 2011.

Durante o governo do presidente Luís Inácio Lula da Silva, a SEESP teve atuação decisiva no desenvolvimento da Política Nacional de Educação Especial na Perspectiva da Educação Inclusiva (Brasil, 2008a). Esta finalmente acabou com a 
possibilidade de se matricular alunos com deficiência, altas habilidades ou transtornos globais do desenvolvimento em escolas ou classes especiais, de maneira substitutiva à escola comum. A nova política materializa, por assim dizer, a vitória decretada do paradigma inclusivista, ao passo que institui uma discursividade consensual, capaz de neutralizar as ambiguidades na interpretação jurídica dos dispositivos legais concernentes à promoção da escola inclusiva.

Sobre esse aspecto, vale recordar que, até 2008 , a ideia de atendimento educacional especializado a ser ofertado preferencialmente na rede regular de ensino ainda deixava aberta a prerrogativa da matrícula de alunos com deficiência apenas em classes ou escolas especiais (Brasil, 1988, 1996). Esse atendimento especializado podia ser entendido, perante certa abstração dos princípios constitucionais genéricos, como a única forma de escolarização a ser destinada aos "deficientes", aceitando-se alternativas segregadas para operacionalizá-lo. Não obstante, ao longo dos anos 2000, o MEC atuou no intuito de desautorizar essa interpretação jurídica, ao insistir no direito de todos a uma educação equânime e conjunta, deflagrando um movimento que culminou com o lançamento oficial daquela política em janeiro de 2008.

O resultado, como se sabe, foi a consequente ressignificação do próprio conceito de educação especial, cuja responsabilidade precípua passou a ser a de organizar, fomentar e apoiar a oferta, no contraturno, do Atendimento Educacional Especializado (AEE) aos os alunos supracitados, em caráter complementar e/ou suplementar, mas não substitutivo à frequência na sala de aula comum. Como locus do AEE, passou-se a admitir tanto as antigas escolas especiais, redefinidas - no entanto, como centros especializados em deficiência devidamente conveniados aos sistemas de ensino -, quanto as escolas públicas regulares, por meio da implantação de salas de recursos multifuncionais, observando-se predominância da oferta de AEE nessas salas, conforme dispõem as diretrizes legais (Brasil, 2009, 2011b, Fávero; Pantoja; Mantoan, 2007).

Mediante os apelos da inclusão total, as deficiências, limitações ou singularidades de quaisquer naturezas deixam de ser tomadas como argumento contrário à entrada e permanência dos estudantes com essas características nas classes regulares. As escolas, sem exceção, precisaram/precisam se readequar para aprender a conviver com as diferenças, transformadas, segundo o discurso dominante, em novo princípio ético e político-pedagógico.

Todavia, pelas nossas leituras, parece que a Política Nacional de Educação Especial na Perspectiva da Educação Inclusiva ainda prossegue imersa em incongruências e rearranjos. Do lado jurídico e financeiro-administrativo, há o reconhecimento estabilizado sobre o direito de todos à matrícula na escola comum, com a explicitação das formas e tempos-espaços de atendimento educacional especializado, além da regulamentação dos recursos financeiros destinados à gestão do AEE (Brasil,2008a, 
2008b, ${ }^{1}$ 2009, 2011b); porém, não se pode dizer o mesmo sobre a configuração político-pedagógica do processo.

Diante do exposto, a imagem da mortalha de Penélope surge como outra analogia a que gostaríamos de recorrer para ilustrar essa problemática, no intuito de captar melhor suas contradições e nuances significativas. Mulher de Odisseu, herói grego que lutara contra os troianos durante vinte anos seguidos, Penélope, ainda jovem e muito bela, fica sozinha em sua casa, em Ítaca, cuidando do filho do casal: Telêmaco. Ela passa, então, a ser disputada por vários pretendentes, os quais buscam apossar-se de seu leito e de seus bens. Esperta, a esposa de Odisseu astucia um estratagema: "Dizia que se casaria com um dos pretendentes após acabar de tecer uma mortalha para o sogro; porém, o que tecia de dia, desmanchava à noite, secretamente. $\mathrm{E}$ assim ia adiando a decisão, pois a mortalha jamais ficava pronta" (Vasconcellos, [1998], p. 81).Cumpre lembrar que, ironicamente, seu sogro, Laertes, sequer morrera, dando a entender que seus pretendentes passariam por um longo tempo de espera.

Da mesma forma, a impressão é de que os governos brasileiros se colocam no lugar de Penélope quanto à educação especial. O que é feito anteriormente por um é desfeito em seguida por outro, quando não pelo mesmo governo, conforme as oscilações das conveniências e interesses políticos do momento. Por isso, a mortalha nunca termina, as decisões são constantemente contraditórias e parciais. Há sempre a marca da ruptura, da descontinuidade na atenção à pessoa com deficiência. Do modelo integrador ao inclusivo, "Sob discursos aparentemente diferentes permanece a mesma concep̧ão de educação especial e sua clientela" (Mazzota, 2005, p. 191, grifos do autor), qual seja, a sua marginalização, explícita ou velada, do sistema escolar como um todo.

Novidadeira, a perspectiva da inclusão é também excludente. Sem grandes transformações no espaço escolar e na sociedade, ela traz novo simulacro à educação especial, porquanto a mantenha como dimensão separada e autônoma do fenômeno educativo, existindo pouca conexão entre as práticas e concepções pedagógicas dos docentes da sala comum e das salas multifuncionais.

1 O decreto n. 7.611, de 17 de novembro de 2011, revogou o decreto n. 6.571, de 17 de setembro de 2008, que dispunha, entre outras questões, sobre o conceito legal e o financiamento do atendimento educacional especializado (AEE) (Brasil, 2008b). Em que pesem as críticas, o decreto n. 7.611, de 2011, manteve, como já fora regulamentado pelo decreto de n. 6. 571 (Brasil, 2008b), o duplo cômputo da matrícula de alunos com deficiência matriculados nas escolas públicas regulares, para efeito de repasse de verbas oriundas do Fundo de Manutenção e Desenvolvimento da Educação Básica e de Valorização dos Profissionais da Educação (FUNDEB). A dupla matrícula é considerada desde que esses estudantes recebam o AEE em salas de recursos multifuncionais ou instituições especializadas do sistema público de ensino ou em instituições comunitárias, confessionais ou filantrópicas sem fins lucrativos, caso estas comprovem atuação exclusiva em educação especial e estejam conveniadas aos órgãos competentes da administração pública (secretarias municipais e/ou estaduais de ensino) (Brasil, 2011b). 
Há, continuamente, um fazer-desmanchar sem fim nos gabinetes ministeriais, que envolvem aspectos gerenciais contraditórios na condução das demandas educacionais postas pelas lutas das pessoas com deficiência, na busca por sua participação em um sistema escolar inclusivo. É preciso ter isso em mente quando se procura entender não apenas o passado, mas também o presente engendrado pelas tramas decorridas.

Desse modo, acreditamos que, findada a primeira década do século XXI, durante a qual o governo federal se encarregou de conduzir o processo de mudança paradigmática, é tempo de questionar o alcance e a validade de uma escola inclusiva, ao menos nas condições em que esta foi, está e continua sendo instituída. A análise seguinte não tem abrangência suficiente para captar todos os fatos e fenômenos implicados, mas pretende colaborar com a tarefa, apresentando ponderações a respeito das implicações politico-educacionais da nova estrutura do MEC, no âmbito da SECADI.

\section{A EXTINÇÃO DA SEESP: (ENTRE)LINHAS POLÍTICAS}

A nova Política Nacional de Educação Especial na Perspectiva da Educação Inclusiva, de 2008, é, portanto, o legado mais recente de uma trajetória de embates e debates que remonta aos anos de 1970. Passado algum tempo, desde sua implementação nas diretrizes oficiais do MEC, esse legado parece não ter ainda se estabilizado nem definido todos os seus rumos com clareza. $\mathrm{Na}$ verdade, é bastante questionável a ideia de que as medidas oficiais, conforme objetivadas no decorrer das últimas décadas, até mesmo agora, possam ser consideradas uma política pública unitária, no tocante à educação especial, sobretudo quando se pensa na fragilidade dos vínculos estabelecidos com a educação em geral.

Frequentemente marginalizado dos interesses oficiais, o ensino especializado aparece, na linha do tempo, mais como pano de fundo a outras políticas nem sempre articuladas às prerrogativas educacionais propriamente ditas, como atesta a preponderância de apelos médico-assistencialistas nas tematizações e concretizações da educação especial, historicamente "[...] interpretada como um apêndice indesejável" (idem, p. 11).

Nessa política de 2008, irrompem as contradições acumuladas no "labirinto", mescladas também aos desafios hodiernos e futuros. ${ }^{2}$ Uma dessas contradições está

2 Vale conferir tais contradições no decreto n. 7.611, de 17 de novembro de 2011. Implicitamente, este traz a prerrogativa de se aceitarem matrículas de alunos com deficiência apenas em escolas ou instituições especiais, contrariando ("desmanchando") as orientações da Politica Nacional de Educação Especial na Perspectiva da Educação Inclusiva, lançada em 2008, pela qual a educação especial passa a ser entendida como complementar/suplementar, mas nunca substitutiva ao ensino regular (Brasil, 2008a, 2008b). Diante disso, o decreto vem sendo objeto de discussão acirrada nos meios acadêmico e jurídico, embora o MEC, por meio de uma nota técnica, alegue não ter havido mudanças em relação à citada política, mantendo assegurado o direito de todos 
na própria essência do movimento inclusivo que tomou forma nos últimos anos, sob a égide do MEC. Nota-se a objetivação de medidas inclusivas paliativas, que não questionam a estrutura socioeconômica excludente e, antes, corroboram para reproduzir, de maneira tácita, a lógica do capital. Como já se dissera, "É próprio dessa lógica de exclusão a inclusão. A sociedade capitalista desenraiza, exclui, para incluir de outro modo, segundo suas próprias regras, segundo sua própria lógica” (Martins, 2009, p. 32, grifos do autor).

$\mathrm{Na}$ direção do exposto, cabe manifestar a necessidade de se exercitar uma reflexão mais totalizante, de caráter dialético sobre o tema. É oportuno perquirir sobre o sentido da proposta inclusiva, que, como fenômeno educacional, não está alienada nem ocorre independentemente das contradições e mediações sociais mais amplas. Vale, pois, considerar,

[...] a histórica posição do Estado em relação à implementação de ações político-educacionais para a inclusão de pessoa com deficiência, discutindo-se em que medida as políticas públicas denominadas inclusivas garantem o acesso à escolarização, uma vez que estamos inseridos numa forma de organização econômica, cultural e social excludente. (Freitas, 2011, p. 221)

$\mathrm{Na}$ esteira dessas considerações, a inclusão de pessoas com deficiência, na direção dada a ela pelo poder público, repetindo, por sua vez, as orientações de organismos supranacionais, tem sido mais uma resposta às necessidades de se forjar consensos em torno do atual modelo societário - para serem mantidas as condições de acumulação e reprodução capitalista - do que componente revolucionário, perturbador da ordem vigente. $\mathrm{Na}$ qualidade de ideário sedutor, a inclusão escolar apresenta-se envolta no bumanismo tardio, difundido, com especial interesse, pelas agências multilaterais, sobretudo o Banco Mundial e a Organização das Nações Unidas para a Educação, Ciência e Cultura (UNESCO). Sendo assim, o discurso "desinteressado" que respeita as diferenças individuais e exalta os direitos humanos, segundo proposições disseminadas por tais organismos, acaba por favorecer a adesão imediata e acrítica das pessoas aos "valores" inclusivistas.

Nessas condições, o ideário inclusivista encontra repercussão conceitual na agenda pós-moderna, produzindo cantos de sereia, tal como aqueles que deixaram o grego Odisseu, esposo de Penélope, encantado, sem controle sobre si mesmo, na volta para casa. Se a aparência da "melodia" é progressista, o conteúdo da "letra" relaciona-se, todavia, à mistificação ideológica, que vem atrelada aos interesses dominantes. Sob

a um sistema educacional inclusivo. $\mathrm{O}$ decreto reacende a disputa entre as tendências de inclusão total e progressiva, sinalizando para a emergência prospectiva de uma tímida reorientação oficial na política de inclusão escolar de pessoas com deficiência, com caráter menos radical do que se observou na primeira década do século XXI (Brasil, 2011b; Nota..., 2011). No entanto, é preciso aguardar as próximas movimentações da SECADI e do governo federal, bem como análises mais substanciais do decreto n. 7.611, de 17 de novembro de 2011, para quaisquer afirmações mais contundentes. 
o lema do aprender a viver juntos (Delors, 1998), os conceitos de diversidade e convivência solidária com as diferenças tornam-se a principal tematização político-pedagógica de nossa época, quando a desigualdade material é ressignificada como atributo cultural, identitário, subjetivo. As diferenças são enaltecidas e integradas aos projetos de governo, tornando mais fácil o controle estatal sobre os "diferentes" e sobre os "grupos minoritários".

Desse modo, oblitera-se o cerne da problemática paradoxalmente levantada pelo próprio discurso em favor da escola inclusiva, qual seja, a necessária democratização da escola, sobretudo aquela ofertada pelo poder público. Escola que hoje enfrenta o desafio sem precedentes de assegurar a todos, indistintamente, ensino de qualidade, capaz de superar as rupturas e barreiras tradicionais entre alunos com e sem deficiência, transformando-se por inteiro, à proporção que mobiliza a sociedade e é por esta mobilizada. Tal como já lembrado,

O desafio da escola comum não é somente com a inclusão de pessoas com deficiências, mas o de uma transformação na sua totalidade pedagógica, tendo em vista as diferenças de todos os alunos. Daí os inúmeros desafios frente às contradições que demarcam as diferentes realidades do contexto nacional se acreditarmos numa educação como processo de mudança e de transformação. (Freitas, 2011, p. 227)

O discurso inclusivista em voga, todavia, tende a limitar o debate às deficiências, além de nutrir-se do salvacionismo reducionista. A escola é interpretada como se tivesse, per se, poderes taumatúrgicos para enfrentar a realidade nacional contraditória e conflituosa que a condiciona. Assim, chega-se ao ponto da idealização romântica, que produz a negação da própria objetividade da deficiência, não obstante sua recorrência nos discursos educacionais. Ser "diferente" é normal e, nessa ordem das ideias, a deficiência se reduz a uma diferença a ser celebrada, "endeusada". Com semelhante mistificação, atinge-se, no máximo, o igualitarismo abstrato, que, paradoxalmente e já no ponto de partida, considera que "Todos se igualam pelas suas diferenças" (Ropoli et al.,2010, p. 8, grifos nossos). Todos são iguais porque são todos diferentes ou "especiais"! Em outras palavras, a diferença passa a ser a nova marca de igualdade. Essa igualdade idealizada, no ponto de partida, tem de ser analisada com mais cuidado. Vejamos por quê.

De início, é preciso considerar que tal igualitarismo se coloca como pseudodemocrático. Em nome dele, força-se uma igualdade formal entre todos os educandos, de modo que todos são vistos como detentores de uma capacidade abstrata para aprender, nas mesmas condições, em que pesem as variações de ritmo e peculiaridades individuais, pois são contraditoriamente igualados pelas suas diferenças. Todos passam a ter necessidades educativas especiais (Correia, 2006). Nesse universo ideológico, são levantados slogans sedutores e bombásticos, porém desprovidos de objetividade, como 
[...] "todos temos necessidades educativas especiais" e suas variantes, "todos somos especiais", "celebremos a diferença", "celebremos a diversidade", "inclusão para todos", "a educação especial já lá vai", e por aí afora - termos usados sem qualquer despudor, a torto e a direito, não só por quem faz educação, mas também por quem pretende vendê-la ao público em geral. Embora popular, essa propaganda afigura-se-me sem sentido, descabida de propósitos... [...]. (Correia, 2006, p. 241, grifos do autor)

Por conseguinte, as complexas mediações pedagógicas reclamadas pela escola que inclui podem ser simplificadas, deixando-se que cada um aprenda do seu "jeitinho", conforme suas possibilidades, pois a aprendizagem seria uma "construção pessoal", a que se regula o aluno, com a mínima interferência docente. Na concepção inclusiva hegemônica, "[...] é o aluno que se adapta ao novo conhecimento, é só ele capaz de regular o seu processo de construção intelectual" (Mantoan, 2007, p. 49, grifos nossos). Destarte, a escola inclusiva acaba por desconsiderar as reais necessidades dos alunos com deficiência. Mantém-se, por essa via, a desigualdade, sob o pretexto de se construir uma escola democrática, que não homogeneíza os estudantes, reconhecendo suas peculiaridades e seus diversos ritmos de aprendizagem. A democracia, porém, está posta somente no nível da aparência, pois,

[...] se a democracia supõe condições de igualdade entre os diferentes agentes sociais, como a prática pedagógica pode ser democrática já no ponto de partida? Com efeito, se [...] a educação supõe a desigualdade no ponto de partida e a igualdade no ponto de chegada, agir como se as condições de igualdade estivessem instauradas desde o início não significa, então, assumir uma atitude pseudodemocrática? Não resulta, em suma, num engodo? (Saviani, 2009a, p. 69)

Desconsidera-se, portanto, que a prática pedagógica em relação às pessoas com deficiência detém uma especificidade teórico-metodológica concreta, dando-se a entender que tudo pode ser resolvido apenas com aceitação e boa vontade, segundo um discurso que eleva a diversidade à condição de fetiche pedagógico. "Mesmo entendendo a filosofia inclusiva como justa e promotora de um contexto escolar melhor para todos, precisamos de muita cautela ao conduzi-la. $\mathrm{O}$ ato de inserir o aluno com necessidades educativas especiais no ensino regular, por si só, seria uma pseudoinclusão [...]" (Silva; Facion, 2009, p. 186).

Essa pseudoinclusão tem se materializado na legislação sobre o tema e no debate educacional, que foca o direito de entrada do aluno na escola comum e intenta assegurar sua permanência, mas deixa em aberto a forma pela qual as garantias dessa escolarização inclusiva seriam operacionalizadas; ao mesmo tempo, esquece-se de que a escola promotora da inclusão está dialeticamente situada na sociedade de classes, de modo que, sozinha, não pode resolver a problemática da exclusão escolar, a qual tanto combate quanto reproduz.

Conseguintemente, vemos emergir uma contradição mais ampla entre o discurso oficial e a prática efetivada. Em meio à retórica bem montada, perde-se de 
vista que, "[...] entre o falar e o fazer, entre o discurso oficial e a ação, existem contradições que requerem a participação de todos" (Marques apud Silva; Facion, 2009, p. 201). Na contramão da razoabilidade analítica, verificamos, assim, a apologia do humano como parte, fragmento e diferença, a que se deve agregar por justaposição. Desarticulam-se os saberes quanto à própria ontologia do ser do homem, com ou sem deficiência, dando-se oportunidade para a fragmentação das lutas sociais diante do imperativo de políticas focais, pontuais, que são mais facilmente digeridas pelo princípio da governabilidade baseada em concessões paliativas, porém inócuas para a transformação da sociedade estabelecida. Diante da perspectiva assim considerada,

O que ocorre, entretanto, sob o manto da universalidade das diferenças sem nenhuma mudança nos modelos políticos organizacionais vigentes, é que se estruturam práticas de políticas públicas inclusivas de maneira isolada da realidade objetiva da exclusão social em nosso país. (Padilha; Caiado, 2010, p. 114)

As alterações ultrarrecentes na estrutura ministerial do MEC corroboram as afirmações antes aqui citadas, fazendo-nos retomar o fio de Ariadne que nos move pelas trilhas do labirinto. As constantes redefinições das políticas públicas, com destaque para aquelas voltadas às pessoas com deficiência, mantendo-se impasses habituais, lembram Penélope, que ia tecendo-desmanchando a mortalha do sogro, enquanto, angustiada, esperava a volta incerta do marido.

O decreto n. 7.480, de 16 de maio de 2011, revogado pelo decreto n. 7.690, de 2 de março de 2012, mas mantendo-se a SECADI, traz à tona justamente o descompasso estrutural entre a proposta de uma política pública inclusiva e a realidade objetiva da exclusão social/educacional manifesta em nosso país.

Podemos pensar no desmanche de muitas conquistas, à medida que um panorama incerto começa a ser tecido. Apesar de ainda existirem muitas dúvidas quanto aos rumos da inclusão escolar de pessoas com deficiência, com novos questionamentos em emergência - entre eles a problemática das interfaces ainda não suficientemente estabelecidas entre sala comum e sala de recursos multifuncionais; as lacunas ainda não resolvidas entre a formação especializada, hoje só em nível de pós-graduação, e a formação generalista dos professores, diante da imperativa necessidade de atuarem em contextos ditos inclusivos; a legitimidade de se admitirem ou não flexibilizações curriculares e até que ponto isso seria adequado para alunos com deficiência; bem como o desafio de se sistematizar, em publicações oficiais, os pressupostos teórico-metodológicos a serem adotados nacionalmente na inclusão escolar, tomando-se por base o rigor das pesquisas de campo e das revisões de literatura existentes -, o MEC promove, por força de decreto, o fechamento da SEESP e a diluição de seus encargos na SECADI.

Essa decisão é também evidência sensível de que as questões pertinentes à educação especial vão caindo novamente para um plano bastante inferior na pauta e na hierarquia do ministério, como no princípio da história. Durante a última década, a banalização das discussões relativas ao tema é arrematada com a prevalência de um projeto inclusivista que homogeneíza a diferença como a nova normalidade, levando 
à indiferença do setor público quanto às especificidades do processo educacional dessa população e do respectivo trabalho docente. $\mathrm{O}$ resultado, em termos gerais, é um retrocesso. Tanto o é que o alerta de Saviani chega à segunda década do século XXI sem resposta concreta. Em 2009, já afirmava o autor que:

Considerada a complexidade do problema inerente a essa modalidade [a educação especial] [...], será necessário instituir um espaço específico para cuidar da formação de professores para essa modalidade de ensino. Do contrário, essa área continuará desguarnecida e de nada adiantarão as reiteradas proclamações referentes às virtudes da educação inclusiva que povoam os documentos oficiais e boa parte da literatura educacional nos dias de hoje. (Saviani, 2009b, p. 153)

Com a educação especial novamente secundarizada no plano educacional, as dúvidas e lacunas supracitadas correm o risco de continuar em aberto. Cursos rápidos e esparsos de formação em serviço não resolverão o problema. Logo, em vez de ter se esgotado, o tema da inclusão escolar ainda é candente, posto levantarem-se sérias indagações sobre a consistência de seus pressupostos filosóficos, assentados sob a estrutura de uma sociedade capitalista e excludente, além de subsistirem insuficiências empíricas e epistemológicas. Para alguns estudiosos, perduram ainda

[...] inúmeros pontos obscuros que precisam ser definidos, quando abordamos a temática da inclusão no ambiente escolar. Um dos pontos refere-se à definição de seu campo de abrangência: a que se destina a inclusão? Estamos tratando da inclusão de indivíduos excluídos do sistema escolar por apresentarem necessidades específicas de aprendizagem ou estamos tratando de políticas sociais que tentam combater a exclusão social por meio da inclusão escolar? (Melo; Lira; Facion, 2009, p. 61)

Entendemos, nessa direção, que o fim da SEESP pode ter sido apressado, no sentido de que demandas muito específicas no campo da educação especial sequer foram superadas. As condições objetivas contradizem, portanto, a medida tomada pelo MEC. Sob o comando da SECADI, em meio às suas múltiplas atribuições, há o risco de se pulverizarem as discussões. Em decorrência disso, o debate entusiasmado sobre as possibilidades abertas pelo advento da escola inclusiva vai sendo esvaziado de conteúdo práxico. Começa a se manifestar a crise do movimento escolar inclusivista, cujas conquistas têm sido limitadas à igualdade jurídica, como o reconhecimento do direito de os alunos com deficiência estar na escola e de ter atendimento especializado no contraturno; passo importante, mas insuficiente, posto esbarrar no aspecto contraditório da escola e da sociedade, alinhavadas pela lógica capitalista, suas práticas segregadoras, o dogmatismo oficial e silêncios na formação docente.

Segundo apuramos do posicionamento de alguns autores, "O panorama atual mostra que as contradições geradas pelas leis ocorreram em virtude da adoção de princípios da inclusão sem um consenso educacional, cultural, social e econômico 
que o legitimasse" (idem, ibidem). O desmanche da SEESP, efetivado como uma decisão técnica da equipe de governo, sem consulta prévia aos educadores e pesquisadores brasileiros, sugere o declínio da capacidade reivindicatória do movimento ou, em outras palavras, explicita sua submissão ao controle estatal.

Nesse sentido, sob a alegação de otimizar a estrutura organizacional do MEC, a nova secretaria, a SECADI, constitui-se, então, num mosaico de temas e interesses diversos, de tal forma que não é preciso esforço para perceber o caráter bastante difuso que deverá marcar sua atuação, haja vista a amplitude dos trabalhos e demandas a serem atendidas. Há, até mesmo, o aumento da fragmentação político-administrativa em um número considerável de diretorias. Estas, conforme o decreto mais recente, de n. 7.690, de 2 de março de 2012, ficam assim constituídas: 1. Diretoria de Políticas de Educação do Campo, Indígena, e para as relações étnico-raciais; 2. Diretoria de Políticas de Alfabetização e Educação de Jovens e Adultos; 3. Diretoria de Políticas de Educação em Direitos Humanos e Cidadania; 4. Diretoria de Políticas de Educação Especial; 5. Diretoria de Políticas de Educação para a Juventude (Brasil, 2012). ${ }^{3}$ De acordo com o artigo 20 do decreto em voga, o n. 7.690/2012, compete à SECADI:

I - planejar, orientar e coordenar, em articulação com os sistemas de ensino, a implementação de políticas para a alfabetização, a educação de jovens e adultos, a educação do campo, a educação escolar indigena, a educação em áreas remanescentes de quilombos, a educação em direitos humanos, a educação ambiental e a educação especial;

II- implementar ações de cooperação técnica e financeira entre a União, Estados, Municípios, Distrito Federal, e organismos nacionais e internacionais, voltadas à alfabetização e educação de jovens e adultos, a educação do campo, a educação escolar indígena, a educação em áreas remanescentes de quilombos, a educação em direitos humanos, a educação ambiental e a educação especial;

III - coordenar ações transversais de educação continuada, alfabetização, diversidade, direitos humanos, educação inclusiva e educação ambiental, visando à efetivação de políticas públicas de que trata esta Secretaria, em todos os níveis, etapas e modalidades; $\mathrm{e}$

3 O decreto n. 7.480/2011 previu quatro diretorias para a SECADI, a saber: 1 . Diretoria de Políticas para a Educação do Campo e Diversidade; 2. Diretoria de Políticas de Alfabetização e Educação de Jovens e Adultos; 3. Diretoria de Políticas de Direitos Humanos e Cidadania; 4. Diretoria de Políticas de Educação Especial. O novo decreto ampliou o raio de ação da SECADI, como se vê, pelo aumento de uma diretoria, bem como substituiu o termo diversidade, da Diretoria 1 do decreto de 2011, pela expressão "Indígena, e para as relações étnico-raciais", objetivando o entendimento do ministério sobre o conceito de diversidade, com destaque às questões étnico-racias e indígenas na referida secretaria. O texto de 2012 reforça também, pela mudança de nome na Diretoria 3, que se trata de fomentar a educação em direitos humanos e cidadania, com abordagem pedagógica da questão, o que não se explicitava antes, na denominação Diretoria de Politicas de Direitos Humanos e Cidadania. 
IV - apoiar o desenvolvimento de ações de educação continuada, alfabetização, diversidade, direitos humanos, educação inclusiva e educação ambiental, visando à efetivação de políticas públicas intersetoriais. (Brasil, 2012, grifos nossos)

Perguntamo-nos se é possível, desse modo, construir políticas intersetoriais com a nova estrutura pretendida pela SECADI ou se, ao contrário, estamos apenas diante de um eufemismo para escamotear a justaposição apressada de temáticas diversas, cujos apelos específicos ainda não foram superados historicamente. A impressão é de que foram postos no mesmo labirinto os assuntos relacionados à categoria diversidade, vista atualmente de maneira tão abstrata e dilatada que já está naturalizada. Alguém poderia objetar que a articulação de diversos campos educacionais não pode, em princípio, ser condenada, mas perseguida como uma dimensão teleológica peculiar à própria dinâmica da educação, a qual almeja a unidade do diverso, a totalidade formativa em oposição à unilateralidade degradante. Sabemos, todavia, pelo retroceder histórico, que no Brasil isso tem acontecido pela via de modismos ecléticos, por imposição de organizações internacionais ou mesmo pela simples conveniência administrativa, "[...] sem nenhuma mudança nos modelos políticos organizacionais vigentes [...]”(Padilha; Caiado, 2010, p. 114).

À luz dessas ponderações, o fim da SEESP, com a subsunção de suas funções no complexo intrincado da SECADI, expressa, pois, a permanência da setorização política e da fragmentação no trato das questões educacionais; na verdade, em vez do todo orgânico, intensifica-se, com a SECADI, o pragmatismo gerencial, porquanto a intersetorialidade significa exatamente um "diálogo" entre setores ainda isolados; independentes e autônomos, em última instância.

Em termos de argumentação gramsciana, para o caso da SECADI, “[...] nada indica que a referência seja a totalidade do sistema ou ao seu núcleo essencial" (Gramsci, 1995, p. 36). Perante o raciocínio considerado, cabe relembrar outro alerta: "Ao contextualizarmos essa política educacional [inclusiva] no conjunto de outras políticas públicas, também setorizadas, para combater a lógica da exclusão social, a probabilidade de insucesso amplia-se consideravelmente [...]" (Mendes, 2006, p. 401).

Apercebendo-se das nuances arriscadas nos rumos tomados pela questão, parcela considerável da comunidade acadêmica especializada expôs publicamente os receios perante essa medida. Foi organizado um manifesto, pedindo a revisão da política nacional de educação inclusiva. No documento, os redatores relatam o distanciamento progressivo da SEESP, a partir de meados dos anos 2000, no tocante à observância dos estudos e pesquisas desenvolvidos na área da inclusão. Disso, teria resultado a emergência gradual de uma postura autoritarista, pela qual as diretrizes políticas da SEESP/MEC foram se tornando "[...] um empreendimento cada vez menos conduzido de forma coletiva e democrática, produzindo resultados que muito têm preocupado à comunidade acadêmica no país" (Manifesto..., 2011).

No texto, é questionado também se, diante dos "[...] problemas crônicos da educação de crianças e jovens com necessidades educacionais especiais [...], esta 
medida [qual seja, o fechamento da SEESP] trará algum benefício para esta parcela da população brasileira, além da possibilidade de contenção de gastos para o atual governo" (idem, ibidem, grifos nossos).

Nessa direção, um aspecto interessante a ser ressaltado está nos dizeres do artigo 20 do decreto n. 7.690/2012. Em virtude desse dispositivo legal, existe a possibilidade de se admitir, além da articulação necessária entre as diferentes instâncias formais do sistema nacional de ensino, a implementação de "[...] ações de cooperação técnica e financeira entre a União, Estados, Municípios, Distrito Federal, e organismos nacionais e internacionais [...]" (Brasil, 2012). Observa-se, pois, a manutenção da proximidade entre as políticas públicas brasileiras, inclusive no caso da inclusão escolar de pessoas com deficiência, com as organizações não governamentais (ONGs), muitas delas vinculadas à iniciativa privada, mas mantidas com recursos do poder público, sob a justificativa de se buscar uma gestão flexível e eficaz. Fica também patente o alinhamento ideológico dessas políticas às exigências e concepções de organismos internacionais, que seguem ditando as regras da inclusão, segundo a (mercado) lógica do custo-benefício (Kassar; Arruda; Benatti, 2007).

Produzida nesse cenário, a SECADI é, ao mesmo tempo, uma grande "totalidade" e um grande vazio, porque lida com uma pretensa complexidade. Nessa linha de raciocínio, pelos delineamentos do decreto n. 7.690/2012, só poderá alcançar seus múltiplos objetivos de maneira precária. $\mathrm{O}$ todo aqui é mais a soma do que a interação recíproca entre as partes. Ademais, essa complexidade, assim dividida em diretorias e subpastas, já não é mais complexidade, senão simplificação do problema em fatores isolados ou pouco inter-relacionados, abstraídos. Fica a interrogação: como será possível à SECADI dirimir, sem uma alteração radical no direcionamento do MEC, as questões indígenas, a alfabetização, a educação de jovens e adultos, a educação do campo, a educação especial, a educação ambiental, a educação quilombola, a educação em direitos humanos, e toda a sorte de mais diversidades que se the acrescentem, senão pela via da fragmentação disciplinar, eufemisticamente denominada de intersetorialidade?

Não se trata, porém, de alardear pessimismo fatalista, nem partidarismo corporativista em relação à educação especial. O cerne da questão deve ser a crítica ao ecletismo fácil que invade essa pasta, sem se notar um eixo, uma concepção filosófico-educacional que lhe dê a devida unidade em torno dos múltiplos apelos suscitados.

$\mathrm{Na}$ realidade, importa alertar para o modo como se pretende (re)conduzir as políticas educacionais no Brasil. Isso significa não prescindir da crítica, da ressignificação de sentidos perdidos ou já deteriorados nos últimos anos, quando o entusiasmo original pela escola de e para todos vai se transformando em simples otimismo pedagógico - para utilizarmos aqui, com certa liberdade, os termos outrora empregados por Nagle (apud Saviani, 2009a), quando de sua análise para caracterizar a educação brasileira nos idos da Primeira República.

Diante do panorama exposto, torna-se necessário retomar o equilíbrio entre teorizar e agir inclusivamente, entre o discurso grandiloquente que inclui e a política 
que o nega, em um cenário identificado pela mera justaposição de reivindicações bastante específicas, que precisam ser examinadas com mais vagar, sob pena de se pulverizarem os esforços políticos, os recursos materiais e humanos a tal ponto que não se conseguirá atingir nenhuma mudança significativa nessa conjuntura socioeducacional.

A saída do labirinto passa pelo (re)encontro desse ponto de equilíbrio nas políticas de inclusão, entendendo-se que a escola não é autônoma dos determinantes sociopolíticos e econômicos, conquanto possa desencadear mudanças consideráveis nos indivíduos e mobilizá-los à transformação social. É tempo de pensar a educação de pessoas com e sem deficiência pelo viés da unidade dialética, de maneira que os contrários (ensino comum e especializado) se interpenetrem, mas não se confundam ou se anulem; antes, produzam uma compreensão qualitativamente superior do fenômeno educativo, com o rechaço de enfoques dicotômicos, preconceituosos e excludentes.

$\mathrm{Na}$ esteira dessas considerações, cumpre não apenas afirmar, idealisticamente, as diferenças individuais dos alunos e as necessidades educacionais delas decorrentes, mas, sobretudo, considerar a significância dessas diferenças

[...] para, assim, podermos respeitar suas características e necessidades e, consequentemente, considerar métodos de ensino adequados e diferenciados [...]; [...] tanto mais que muitas das respostas educativas para os alunos com NEE requerem qualidade, estruturação e eficiência, atributos sem os quais não é possível dar resposta às necessidades diárias dos alunos com NEE. (Correia, 2006, p. 242 e 265)

Não podemos, entretanto, deixarmo-nos levar pelos apelos da igualdade abstrata e da mera exaltação fetichizada das singularidades individuais. Tais medidas cativam e "acolhem" no plano do discurso, embora concretamente mascarem e legitimem a desigualdade real, haja vista que

A retórica do igualitarismo, quando este não se vê dentro de uma perspectiva das nossas necessidades, das diferenças significativas que alguns de nós possuem, embora possa encantar e seduzir aqueles menos preparados, não passa disso mesmo: uma discussão palavrosa, pobre de ideias. (idem, p. 241)

O momento para retomar o entusiasmo crítico, que redunde em ações transformadoras, em vez do conformismo e da passividade otimistas, está posto objetivamente neste momento, em que a SEESP é extinta e a educação especial inclusiva passa a integrar a SECADI. Vislumbra-se uma oportunidade para a retomada do debate perdido no cenário da inclusão escolar, mediante a denúncia e o acirramento das contradições ora apresentadas. Estas devem ser a substância catalisadora para o esboço de um novo projeto de inclusão escolar, que tenha como premissa básica o conhecimento desmistificado das deficiências e outras condições 
humanas singulares, promovendo-se a superação do sentimentalismo indulgente, da negligência pedagógica e das lacunas na formação docente.

Ao mesmo tempo, não se poderá olvidar que a escola inclusiva precisa levar a um questionamento cada vez maior acerca da organização social classista e meritocrática existente à sua base, pois a superação da exclusão escolar deve alinhar-se, reciprocamente, com a superação da sociedade que (re)produz essa lógica excludente; do contrário, a propalada inclusão escolar redundará em uma pedagogia ingênua, não crítica, isto é, aquela que "[...] concebe a educação com uma ampla margem de autonomia em face da sociedade. Tanto que lhe cabe um papel decisivo na conformação da sociedade evitando sua desagregação e, mais do que isso, garantindo a construção de uma sociedade igualitária” (Saviani, 2009a, p. 4), ou, para usar o jargão da moda, de uma sociedade includente.

No bojo dessas formulações, há que se (re)estabelecer um intenso diálogo intrainstitucional, fundamentado na troca de informações e posturas teórico-metodológicas entre professores das salas de aula comum e professores da sala de recursos multifuncionais, onde tem ocorrido prioritariamente o AEE; bem como se advoga o fortalecimento da comunicação interinstitucional, o que pressupõe a aproximação entre a escola regular, as diversas instituições especializadas, as associações de familiares de pessoas com deficiência e as universidades.

A totalidade é construção coletiva, não decretada. Da pluralidade dos diálogos e práticas pode resultar uma contraproposta a ser apresentada para o governo e para as escolas, com vistas a se garantir coerência epistemológica e correspondência empírica no (re)direcionamento da inclusão escolar. Claro está que se há de tomar sempre, como ponto de partida e ponto de chegada, a recusa de quaisquer formas de segregacionismo, pois não se está advogado o retorno de uma educação especial praticada em instituições isoladas, desconectadas da educação comum.

Antes, de modo particular neste texto, deve-se buscar demonstrar a importância de uma intervenção educacional condizente com as demandas apresentadas pelos alunos com deficiência, sendo esta prática mediada por "[...] um conjunto de estratégias e métodos, já comprovados pela investigação, que possam responder à variedade de características que eles apresentam (Heward, 2003; Kauffman, 2002)" (Correia, 2006, p. 267). Isso se quisermos ir além da retórica igualitarista em torno das diferenças, a qual se consubstancia, ao final, em negligência dissimulada.

Por sua vez, o objetivo pedagógico de incluir, posto como imperativo ético e político da atualidade, não se pode limitar ao universo escolar, mas deverá suscitar a renovação do compromisso político emancipador, que pressupõe competência técnica, de maneira que se tenha, como perspectiva teórico-prática, este intento: "[...] criar um sistema de educação que lhes assegure [a todos os homens, indistintamente] um desenvolvimento multilateral e harmonioso que dê a cada um a possibilidade de participar enquanto criador em todas as manifestações de vida humana" (Leontiev, 1978, p. 284). 


\section{CONSIDERAÇÕES FINAIS}

O panorama é, portanto, de tensão e embate entre o passado e o presente, convidando-nos a uma releitura crítica das políticas públicas em educação, se o objetivo é defendermos uma nova configuração regimental, diferente da que ora se impõe pelo decreto n. 7.690, de 2 de março de 2012. É tempo de recuperar significações perdidas na década recém-terminada, voltando-nos aos anseios e reivindicações dos sujeitos que, de fato, precisam ter atendidas suas necessidades pedagógicas no interior de uma escola verdadeiramente democrática, mais do que simplesmente serem acolhidos e "celebrados" em suas diferenças.

Há também que se questionar o sentido precípuo de falarmos em referenciais e paradigmas inclusivos em um contexto social que se nutre da lógica desagregadora do capital e subordina as relações pedagógicas às pressões emanadas de governos e organismos representativos da ideologia capitalista, no bojo da racionalidade financeira e pragmática.

Desse panorama, compreendemos que a viabilidade do que propõe a SECADI pode estar comprometida pela justaposição temática e fragmentação mosaica que a perpassam. $\mathrm{O}$ uso de algumas metáforas neste trabalho foi, portanto, uma tentativa de ilustrar, com maior carga semântica e aproximação figurativa, esses desafios, contradições e expectativas, engendrados pelos imbricamentos entre a conjuntura política atual e a passada, quanto à inclusão escolar de pessoas com deficiência.

Lançamos a imagem do labirinto onde Teseu enfrenta o Minotauro, guiando-se pelo fio de Ariadne, a fim de desenharmos um percurso metodológico e estilístico que, aos poucos, possibilitou-nos vislumbrar uma porta de saída. Situamo-la, sobretudo, na busca pela retomada do equilíbrio entre o conteúdo das proposições filosóficas do movimento inclusivo, já bastante desfiguradas, e seus condicionantes sociais e pedagógicos. Assim, foi possível esboçarmos uma reação contra as artimanhas sedutoras do idealismo, o qual, sob a apoteose das diferenças, deposita na escola toda a responsabilidade pela mudança da realidade excludente, enquanto ratifica desigualdades.

A mortalha de Penélope colocou-nos, por sua vez, perante o (des)fazer ministerial, ao simbolizar o tratamento contraditório que o MEC tem, ao longo do tempo, dado às demandas postas pela educação especial (e) inclusiva: criando órgãos administrativos, fechando-os, substituindo-os ou até mesmo os reativando, sem sinalizar, no entanto, para uma diretriz unificada e coerente na condução de exigências educacionais tão complexas.

Nesse sentido, passada a fase do entusiasmo inicial, cumpre-nos empreender esforços para a reabertura do debate acerca das políticas educacionais voltadas à inclusão escolar, compreendo-as em sua totalidade. $\mathrm{O}$ manifesto da comunidade acadêmica especializada, recentemente divulgado, via internet, a pesquisadores, estudiosos e interessados no assunto, com o propósito maior de reivindicar uma 
revisão coletiva na política nacional de educação inclusiva, é sinal indicativo que precisa ser levado em conta pelo MEC.

Encontrada a ponta do novelo, novos estudos ainda são necessários para indicar, em mais detalhes, o caminho a ser objetivamente trilhado. Não na perspectiva do fazer-desmanchar de Penélope, mas com a troca dos fios gastos por fios novos, a fim de que surjam, enfim, mudanças significativas na forma e no conteúdo das tramas político-pedagógicas.

Entre o fio de Ariadne e a mortalha de Penélope, encontra-se a chave para entendermos crítica e heuristicamente o desafio proposto na recente conjuntura. Vale dizer, o desafio de perscrutar a saída do labirinto donde se tem emaranhado o novelo das políticas públicas brasileiras, com destaque para aquelas voltadas para a educação especial inclusiva, cujos fios, mediante a implantação da SECADI, cruzam-se agora com outras políticas (inter)setorizadas, compondo uma colcha de retalhos.

\section{REFERÊNCIAS}

Beyer, Hugo Otto. O. Inclusão e avaliação na escola: de alunos com necessidades educacionais especiais. 3. ed. Porto Alegre: Mediação, 2010.

Brasil. Decreto n. 72.425, de 3 de julho de 1973. Cria o Centro Nacional de Educação Especial (CENESP), e dá outras providências. Diário Oficial da União, Brasília, DF, 4 jul. 1973. Disponível em: <http://www6.senado.gov.br/legislacao/ListaTextoIntegral. action?id=186315>. Acesso em: 6 set. 2011.

Decreto n. 93.613, de 21 de novembro de 1986. Extingue órgãos do Ministério da Educação, e dá outras providências. Diário Oficial da União, Brasília, DF, 24 nov.1986. Disponível em: <http://www.planalto.gov.br/ccivil_03/decreto/1980-1989/1985-1987/ D93613.htm>. Acesso em: 6 set. 2011.

. Constituição da República Federativa do Brasil de 1988. Diário Oficial da União, Brasília, DF, 5 out. 1988. Disponível em: <http://www.planalto.gov.br/ccivil_03/ constituicao/constitui\%C3\%A7ao.htm>. Acesso em: 6 set. 2011.

.Decreto n. 99.678, de 8 de novembro de 1990. Aprova a Estrutura Regimental do Ministério da Educação e dá outras providências. Diário Ofcicial da União, Brasília, DF, 9 nov. 1990. Disponível em: <http://www.planalto.gov.br/ccivil_03/decreto/Antigos/ D99678.htm>. Acesso em: 6 set. 2011.

. Lei n. 8.490 de 19 de novembro de 1992. Dispõe sobre a organização da Presidência da República e dos Ministérios e dá outras providências. Diário Oficial da União, Brasília, DF, 19 nov. 1992. Disponível em: <http://www010.dataprev.gov.br/ sislex/paginas/42/1992/8490.htm>. Acesso em: 6 set. 2011.

. Ministério a Educação. Lei n. 9.394, de 20 de dezembro de 1996. Estabelece as Diretrizes e Bases da Educação Nacional. Diário Oficial da União, Brasília, DF, 23 dez. 1996. Disponível em: <http://www.planalto.gov.br/ccivil_03/leis/L9394.htm>. Acesso em: 6 set. 2011. 
Ministério da Educação. Política Nacional de Educação Especial na Perspectiva da Educação Inclusiva. MEC/SEESP, 2008a. Disponível em: < http://portal.mec.gov.br/ arquivos/pdf/politicaeducespecial.pdf>. Acesso em: 29 jul. 2010.

Decreto n. 6.571, de 17 de setembro de 2008. Dispõe sobre o atendimento educacional especializado, regulamenta o parágrafo único do artigo 60 da lei n. 9.394, de 20 de dezembro de 1996, e acrescenta dispositivo ao decreto n. 6.253, de 13 de novembro de 2007. Diário Oficial da União, Brasília, DF, 18 set. 2008b. Disponível em: <http://www.planalto.gov.br/ccivil_03/_Ato2007-2010/2008/Decreto/D6571.htm>. Acesso em: 13 jan. 2010.

. Ministério da Educação. Conselho Nacional de Educação. Câmara de Educação Básica. Resolução n. 4, de $1^{\circ}$ de outubro de 2009. Institui Diretrizes Operacionais para o Atendimento Educacional Especializado na Educação Básica, modalidade Educação Especial. Diário Oficial da União, Brasília, DF, 5 out. 2009. Disponível em: <http://www. cesarcallegari.com.br/v1/edesp.pdf>. Acesso em: 21 abr. 2011.

Decreto n. 7.480, de 16 de maio de 2011. Aprova a Estrutura Regimental e o Quadro Demonstrativo dos Cargos em Comissão do Grupo-Direção e Assessoramento Superiores (DAS) e das Funções Gratificadas do Ministério da Educação e dispõe sobre remanejamento de cargos em comissão. Diário Oficial da União, Brasília, DF, 17 maio 2011a. Disponível em: <https:/www.planalto.gov.br/ccivil_03/_ato2011-2014/2011/ decreto/d7480.htm>. Acesso em: 6 set. 2011.

Decreto n. 7.611, de 17 de novembro de 2011. Dispõe sobre a educação especial, o atendimento educacional especializado e dá outras providências. Diário Oficial da União, Brasília, DF, 18 nov. 2011b. Disponível em: <http://www.planalto.gov.br/ ccivil_03/_Ato2011-2014/2011/Decreto/D7611.htm\#art8>.Acesso em: 24 dez. 2011.

Decreto n. 7.690, de 2 de março de 2012. Aprova a Estrutura Regimental e o Quadro Demonstrativo dos Cargos em Comissão e das Funções Gratificadas do Ministério da Educação. Diário Oficial da União, Brasília, DF, 6 mar. 2012. Não paginado. Disponível em: <http:/www.planalto.gov.br/ccivil_03/_Ato2011-2014/2012/Decreto/ D7690.htm>. Acesso em: 27 maio 2012.

Bueno, José Geraldo Silveira. Educação especial brasileira: integração/segregação do aluno diferente. São Paulo: Educ, 1993.

Correia, Luís de Miranda. Dez anos de Salamanca, Portugal e os alunos com necessidades educativas especiais. In: Rodrigues, David (Org.). Inclusão e educação: doze olhares sobre a educação inclusiva. São Paulo: Summus, 2006. p. 239-274.

Delors, Jacques (Org.). Educação: um tesouro a descobrir. São Paulo: Cortez; Brasília: MEC/UNESCO. Tradução de José Carlos Eufrázio, 1998. Disponível em: <http:// www.dhnet.org.br/dados/relatorios/a_pdf/r_unesco_educ_tesouro_descobrir.pdf >. Acesso em: 1 dez. 2011.

FÁvero, Eugênia Augusta Gonzaga; Pantoja, Luísa de Marillac Xavier dos Passos; Mantoan, Maria Teresa Eglér. Atendimento educacional especializado: aspectos legais e orientações pedagógicas. São Paulo: MEC/SEESP, 2007. 
Freitas, Soraia Napoleão. O direito à educação para a pessoa com deficiência: considerações acerca das políticas públicas. In: BAPTista, Cláudio Roberto; Jesus, Denise Meyrelles de (Orgs.). Avanços em politicas de inclusão: o contexto da educação especial no Brasil e em outros países. 2. ed. Porto Alegre: Mediação, 2011. p. 221-228.

Gramsci, Antonio. Concepşão dialética da história. 10. ed. Rio de Janeiro: Civilização Brasileira. Tradução de Carlos Nelson Coutinho, 1995.

Januzzi, Gilberta de Martino. A educação do deficiente no Brasil: dos primórdios ao início do século XXI. 2. ed. Campinas: Autores Associados, 2006.

Kassar, Mônica de Carvalho Magalhães; Arruda, Elcia Esnarriaga de; Benatti, Marielle Moreira Santos. Políticas de inclusão: o verso e o reverso de discursos e práticas. In: Jesus, Denise Meyrelles de; Baptista, Cláudio Roberto; Barreto, Maria Aparecida Santos Corrêa; VIctor, Sônia Lopes (Orgs.). Inclusão, práticas pedagógicas e trajetórias de pesquisa. Porto Alegre: Mediação, 2007. p. 21-31.

Leontiev, Alexis N. O desenvolvimento do psiquismo. Tradução de Manuel Dias Duarte. Lisboa: Livros Horizonte. 1978.

Manifesto da Comunidade Acadêmica pela Revisão da Política Nacional de Educação Inclusiva. 2011. [s. 1.: s.n.]. Não paginado. Disponível em: <http://www. peticaopublica.com.br/PeticaoVer.aspx?pi=P2011N11492>. Acesso em: 6 set. 2011.

Mantoan, Maria Teresa Eglér. Educação inclusiva: orientações pedagógicas. In: Fávero, Eugênia Augusta Gonzaga; Pantoja, Luísa de Marillac Xavier dos Passos; Mantoan, Maria Teresa Eglér. Atendimento educacional especializado: aspectos legais e orientações pedagógicas. São Paulo: MEC/SEESP, 2007. p. 45-60.

Martins, José de Souza. Exclusão social e a nova desigualdade. 4. ed. São Paulo: Paulus, 2009.

Mazzotta, Marcos José Silveira. Educação especial no Brasil: história e políticas públicas. 5. ed. São Paulo: Cortez, 2005.

Melo, Sandra Cordeiro de; Lira, Solange Maria de; Facion, José Raimundo. Políticas inclusivas e possíveis implicações no ambiente escolar. In: FAcion, José Raimundo (Org.). Inclusão escolar e suas implicaçôes. 2. ed. rev. e atual. Curitiba: Ibpex, 2009. p. 53-76.

Mendes, Enicéia Gonçalves. A radicalização do debate sobre inclusão escolar no Brasil. Revista Brasileira de Educação, Rio de Janeiro: ANPED; Campinas: Autores Associados, v. 11, n. 33, p. 389-406, set./dez. 2006. Disponível em: <http://www.scielo.br/pdf/rbedu/ v11n33/a02v1133.pdf>. Acesso em: 6 set. 2011.

Nota tÉcnica n. 62, de 8 de dezembro de 2011. Secretaria de Educação Continuada, Alfabetização, Diversidade e Inclusão: apresentação. Diretoria de Políticas de Educação Especial. Inclusão Já, [s.1.]. 2011. Disponível em: <http://inclusaoja.com.br/tag/mec/> . Acesso em: 27 maio 2012.

Padilha; Adriana Cunha; Caiado, Kátia Regina Moreno. Marcas da exclusão e da inclusão social e educacional: uma reflexão a partir do município de Campinas/SP. In: Mendes, Enicéia Gonçalves; Almeida, Maria Amélia (Orgs.). Das margens ao centro: 
perspectivas para as políticas e práticas educacionais no contexto da educação especial inclusiva. Araraquara: Junqueira \& Marin, 2010. p. 111-119.

Ropoli, Edilene Aparecida; Mantoan, Maria Teresa Eglér; Santos, Maria Terezinha da Consolação Teixeira dos; Machado, Rosângela. A educação especial na perspectiva da inclusão escolar: a escola comum inclusiva. Brasília: MEC/SEESP; Fortaleza: Universidade Federal do Ceará, 2010.

Saviani, Dermeval. Escola e democracia. 41. ed. Campinas: Autores Associados, 2009a. . Formação de professores: aspectos históricos e teóricos do problema no contexto brasileiro. Revista Brasileira de Educaşão, Rio de Janeiro: ANPEd; Campinas: Autores Associados, v. 14, n. 40, p. 143-155, jan./abr. 2009b. Disponível em: <http://www.scielo. br/pdf/rbedu/v14n40/v14n40a12.pdf $>$. Acesso em: 16 fev. 2012.

Silva, Maria de Fátima Minetto Caldeira; Facion, José Raimundo. Perspectivas da inclusão escolar e sua efetivação. In: FAcion, José Raimundo (Org.). Inclusão escolar e suas implicações. 2. ed. rev. e atual. Curitiba, Ibpex, 2009. p. 185-216.

Vasconcellos, Paulo Sérgio de. Mitos gregos. São Paulo: Objetivo/Sol, [1998].

\section{SOBRE OS AUTORES}

Giovani Ferreira Bezerra é mestre em educação pela Universidade Estadual de Mato Grosso do Sul (UEMS). Professor assistente da Universidade Federal de Mato Grosso do Sul (UFMS).

E-mail: gfbezerra@gmail.com

Doracina Aparecida de Castro Araujo é doutora em educação pela Universidade Estadual de Campinas (UNICAMP). Professora da Universidade Estadual de Mato Grosso do Sul (UEMS).

E-mail: doracina@gmail.com

Recebido em junho de 2012

Aprovado em agosto de 2012 
GIOVANI FERREIRA BEZERRA

E DORACINA APARECIDA DE CASTRO ARAUJO

Novas (re)configurações no Ministério da Educação: entre o fio de Ariadne e a mortalha de Penélope

A publicação do decreto n. 7.690, de 2 de março de 2012, incita o revigoramento do debate sobre as políticas públicas no cenário educacional brasileiro, precipuamente quanto à inclusão escolar de pessoas com deficiência, ao sinalizar para um novo arranjo no Ministério da Educação (MEC). No atual contexto, extingue-se a Secretaria de Educação Especial (SEESP) e suas atribuições são remanejadas para a pasta mosaica da Secretaria de Educação Continuada, Alfabetização, Diversidade e Inclusão (SECADI). Compreender o impacto de tal reestruturação ministerial sobre a continuidade do projeto inclusivista em nosso país é, pois, o objetivo central deste trabalho, que para tanto recupera notas históricas e metáforas gregas, na tentativa de desvelar, levantando-se posicionamentos axiológicos sobre o tema, as contradições imbricadas nesse processo de (re)configuração política do MEC.

Palavras-chave: políticas públicas; educação especial; inclusão escolar. 


\section{New (re)configurations in the Ministry of Education: between Ariadne's thread and Penelope's shroud}

The publication of decree $n$. 7.690, of march 2, 2012, stimulates the reinvigoration of the debate on public policy in the Brazilian educational scenario, primarily on the educational inclusion of people with disabilities, indicating a new arrangement in the Ministry of Education (MEC). In the current context, the Special Education Department (SEESP) has been extinguished, and its functions have been relocated to the mosaic Department of Lifelong Education, Literacy, Diversity and Inclusion (SECADI). The purpose of this article is to understand the impact of such ministerial restructuring on the continuity of the inclusive project in Brazil; for this, it resumes historical notes and Greek metaphors in an attempt to unravel, by examining axiological positions about the subject, the contradictions imbricated in the process of political (re)configuration of MEC.

Keyrwords: public policy; special education; school inclusion.

\section{Nuevas (re)configuraciones en el Ministerio de Educación: entre el hilo de Ariadna y la mortaja de Penélope}

La publicación del decreto n. 7.690, el 2 de marzo 2012, induce al fortalecimiento del debate acerca de las politicas públicas en el escenario educativo brasileño, principalmente en la inclusión escolar de personas discapacitadas, señalando una nueva disposición en el Ministerio de Educación (MEC). En el actual contexto, se extingue la Secretaría de Educación Especial (SEESP), y sus funciones se trasladan a la mosaica Secretaría de Educación Continuada, Alfabetización, Diversidad e Inclusión (SECADI). Comprender el impacto de tal reestructuración ministerial en la continuidad del proyecto inclusivo en nuestro pais es el propósito de este trabajo, que, para ello, recupera notas históricas y metáforas griegas, con intento de desentrañar, planteando posiciones valorativas sobre el tema, contradicciones entrelazadas en el proceso de (re)configuración política del MEC.

Palabras clave: políticas públicas; educación especial; inclusión escolar. 